\title{
Decubitus CT Myelography for Detecting Subtle CSF Leaks in Spontaneous Intracranial Hypotension
}

\author{
DP.G. Kranz, DL. Gray, and DT.J. Amrhein
}

\begin{abstract}
SUMMARY: Spontaneous intracranial hypotension is caused by spinal CSF leaks, but the site of the leak is not always detected on spinal imaging. We report on the additional value of decubitus positioning during CT myelography in enhancing the detection of subtle leaks.
\end{abstract}

ABBREVIATIONS: $\mathrm{CTM}=\mathrm{CT}$ myelography; $\mathrm{CVF}=\mathrm{CSF}$ venous fistula; $\mathrm{SIH}=$ spontaneous intracranial hypotension

S pontaneous intracranial hypotension $(\mathrm{SIH})$ is a condition caused by spinal CSF leaks, either into the epidural space or into an adjacent vein, known as a CSF venous fistula (CVF). ${ }^{1,2}$ Detection of CSF leakage on spinal imaging helps confirm the diagnosis and is critical to guiding treatment. ${ }^{3}$ Targeted treatment with epidural patching or surgery is important in refractory cases but requires accurate localization of a leak site. ${ }^{4}$ However, spine imaging does not demonstrate the leak site in approximately half of patients with known SIH., ${ }^{5,6}$ These cases with negative findings on imaging are thought to be due to a low-flow CSF leak or occult CVF. $^{2}$

Imaging techniques that can help improve detection of occult leaks are therefore desirable. We have observed that placing a patient in the lateral decubitus position for CT myelography (CTM) facilitates the detection of CSF leaks in some patients with SIH.

\section{MATERIALS AND METHODS Subjects}

This is a retrospective series of 5 patients with SIH treated between February 2016 and February 2018 in which an etiology of CSF leak was identified on CTM performed with the patient in the lateral decubitus position. The leak was not seen on previously performed prone or supine CTM. The work in this study was approved by the Duke University Medical Center institutional review board and is compliant with the Health Insurance Portability and Accountability Act.

Received November 28, 2018; accepted after revision December 22.

From the Department of Radiology, Duke University Medical Center, Durham, North Carolina.

Please address correspondence to Peter G. Kranz, MD, Department of Radiology, Box 3808, Duke University Medical Center, Durham, NC 27710; e-mail: peter.kranz@ duke.edu; @PeterGKranz

http://dx.doi.org/10.3174/ajnr.A5995
All subjects met International Classification of Headache Disorders, 3rd ed (https://www.ichd-3.org/) criteria for SIH. Brain MR imaging with contrast was performed before spine myelography. In all cases, subjects had undergone at least 1 myelogram with standard prone or supine positioning, which had not definitively localized a leak.

\section{Decubitus Myelogram Technique}

Decubitus CTM was performed on the basis of a subtle abnormality seen on the initial nondecubitus CTM in 4 of 5 patients. In these patients, the decubitus CTM was obtained as part of a dynamic myelogram under fluoroscopy. ${ }^{7}$ In a dynamic myelogram, intrathecal contrast is injected with the patient in the decubitus position; in these 4 patients, the abnormality seen on the initial prone CTM determined whether right or left decubitus positioning was used. The patient was not rolled before CTM to maintain a high density of dependently layering contrast material, and the CTM was performed within 10-15 minutes after fluoroscopic imaging was completed.

In the remaining patient, decubitus CTM of the spine was performed because previous prone CT myelograms had been unrevealing. In this case, bilateral decubitus scans were obtained immediately after the initial prone CTM did not show a leak.

For all myelograms (both prone and decubitus), $10 \mathrm{~mL}$ of iopamidol containing $300 \mathrm{mg} / \mathrm{mL}$ of iodine (Isovue-M 300; Bracco, Princeton, New Jersey) was used. All scans were performed on a single 64-detector row CT scanner (Discovery $750 \mathrm{HD}$; GE Healthcare; Milwaukee, Wisconsin) using the following parameters: helical scan mode, rotation time $=0.8$ seconds, pitch $=0.969$, tube voltage $=120 \mathrm{kV}$ (peak), automated exposure control, tube current $=300-800 \mathrm{~mA}$, noise index $=19.5$, slice thickness $=2.5 \mathrm{~mm}$, interval $=2.5 \mathrm{~mm}$, reconstruction thickness $=0.625 \mathrm{~mm}$. Initial prone myelograms of the entire spine were obtained; when further interrogation of a suspected abnor- 

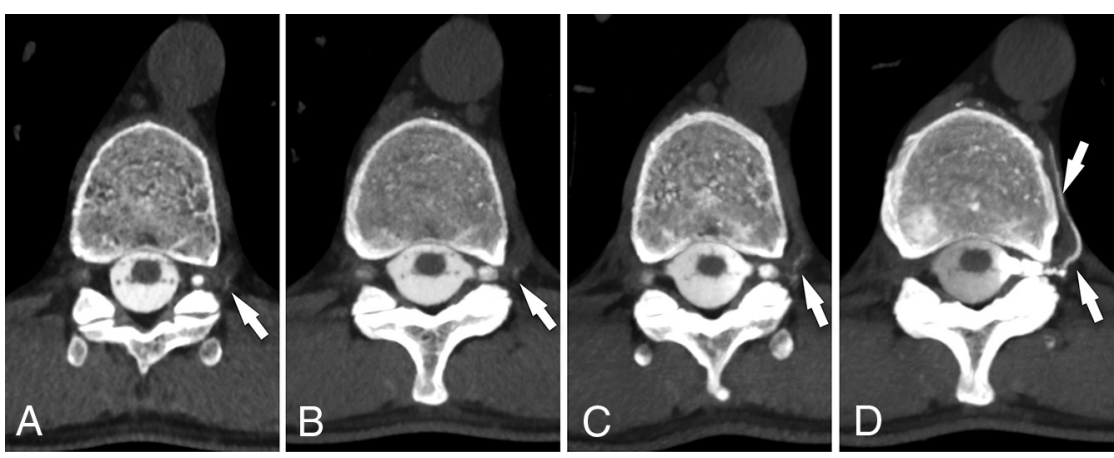

FIG 1. CSF venous fistula visualized best on decubitus CTM. Axial prone CTM image $(A)$ and maximum-intensity-projection image of the same level $(B)$ show subtle linear contrast (arrows) lateral to the $\mathrm{Tl1}$ nerve root. The patient was turned to the left lateral decubitus position and re-scanned 13 minutes later. Axial MIP image $(C)$ from that scan shows increased intravascular contrast with the patient in the decubitus position, suggestive of a CSF venous fistula (arrow). Axial MIP image $(D)$ from a CTM performed after dynamic myelography on a subsequent day with the patient maintained in the decubitus position after contrast injection shows extensive filling of a paraspinal vein distal to the fistula (arrows).
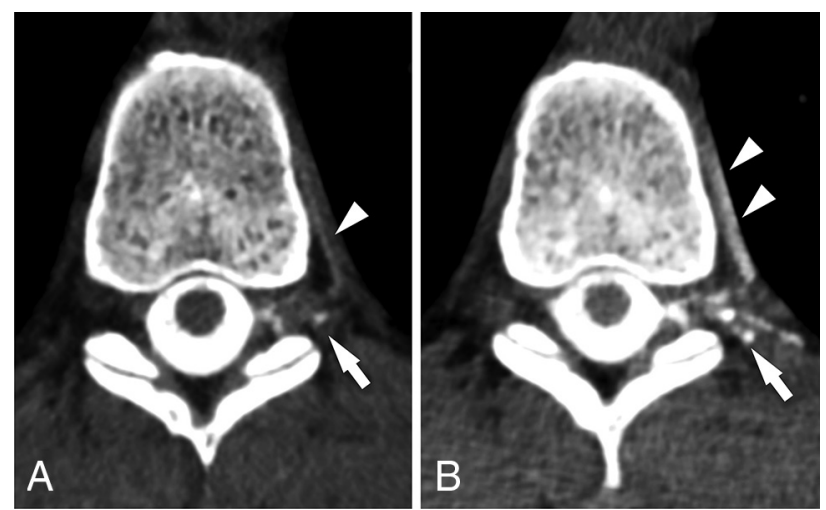

FIG 2. CSF venous fistula visualized best on decubitus CTM. Axial prone CT myelogram $(A)$ shows subtle filling of a network of paraspinal veins (arrow) lateral to the nerve root and in the adjacent spinal segmental vein (arrowhead). Axial image (B) from a decubitus CTM performed after dynamic myelography on a subsequent day shows increased filling of the lateral veins (arrow) and segmental vein (arrowheads), making the CVF much more conspicuous.
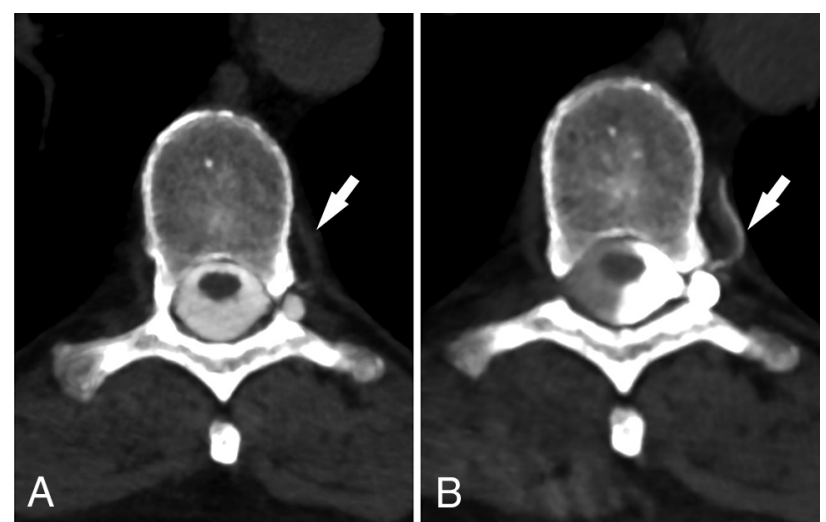

FIG 3. CSF venous fistula visualized best on decubitus CTM. Axial prone CTM image $(A)$ shows possible increased density of a spinal segmental vein (arrow). Axial image (B) from a decubitus CTM performed after dynamic myelography on a subsequent day shows increased filling of the segmental veins (arrow), helping to confirm the diagnosis of CVF. Note the increased density of the left lateral thecal sac due to decubitus positioning. mality was desired, the scan was limited to the area of interest to decrease the radiation dose.

\section{Image Analysis}

The effect of decubitus positioning on the density of intrathecal contrast media was measured by placing an ROI over the thecal sac immediately adjacent to the identified leak. In cases in which a CSF venous fistula was detected, the density of the draining vein was similarly measured, as previously described. ${ }^{8}$

\section{RESULTS}

The mean subject age was 54.2 years (range, 31-72 years). Three subjects were women. Pretreatment brain MR imaging showed evidence of $\mathrm{SIH}$ in all cases. Spine MR imaging was performed before myelography in $3 / 5$ subjects and was negative for CSF leak in all cases. The mean number of CTM examinations performed before the decubitus myelogram was 1.6 (range, 1-3).

Decubitus imaging revealed a CVF in the 4 cases in which a subtle abnormality was questioned on a prior CTM (Figs 1-4). The fistulas in each of these 4 cases were located at the T7, T8, T10, or T11 nerve roots, respectively, all on the left. All 4 CVFs were associated with nerve root sleeve diverticula, a common association reported in other series. ${ }^{7}$ In the case in which bilateral decubitus CTM was performed, a low-flow CSF leak into the epidural space was detected at $\mathrm{T} 10-11$, which was not seen on the prior CTM (Fig 5).

On decubitus CTM, the mean density of intrathecal CSF at the leak site was $1944 \mathrm{HU}$ (range 834-2960 HU), compared with 729 $\mathrm{HU}$ (range, 395-1253 HU) on the prior nondecubitus CTM, representing a mean increase of $301 \%$ on decubitus imaging.

For the cases of CVF, the mean density of the draining paraspinal veins on the decubitus CTM was $294 \mathrm{HU}$ (range, 111-514 $\mathrm{HU}$ ), compared with $104 \mathrm{HU}$ (range, 28-288 HU) on prior nondecubitus CTM, a mean increase of $507 \%$.

\section{DISCUSSION}

This investigation demonstrates the additional yield of CTM performed with the patient in the lateral decubitus position in some patients with SIH when initial prone or supine CTM has not been revealing. In most patients in this series, the decision to perform decubitus imaging was prompted by an initial suspicion of a subtle abnormality on prior CTM, and decubitus myelography confirmed an abnormality at the initially suspected level in these cases. In at least 1 patient, however, decubitus CTM detected a leak that was not visible even in retrospect on prior imaging. Moreover, in the cases in which a CVF was suspected on prior CTM, the initial findings were often very subtle and decubitus myelography greatly increased diagnostic confidence. This increased confidence was a critical factor in committing the patient to surgery. ${ }^{7}$

Two factors may contribute to the increased detection of CSF

AJNR Am J Neuroradiol 40:754-56 Apr 2019 www.ajnr.org 

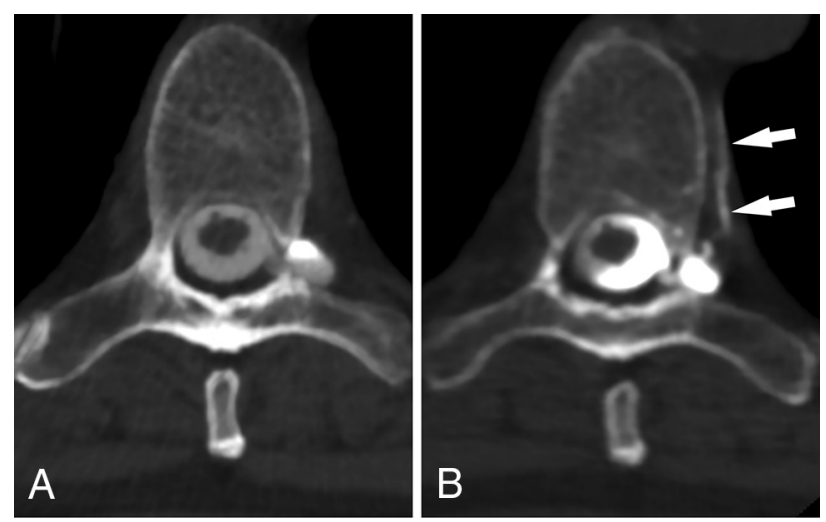

FIG 4. CSF venous fistula visualized best on decubitus CTM. Axial prone CTM image $(A)$ shows a perineural diverticulum, but no clear leak. Axial image $(B)$ from a subsequent CTM obtained with the patient in the decubitus position after dynamic myelography shows clear filling of a segmental vein (arrows), confirming a CVF.
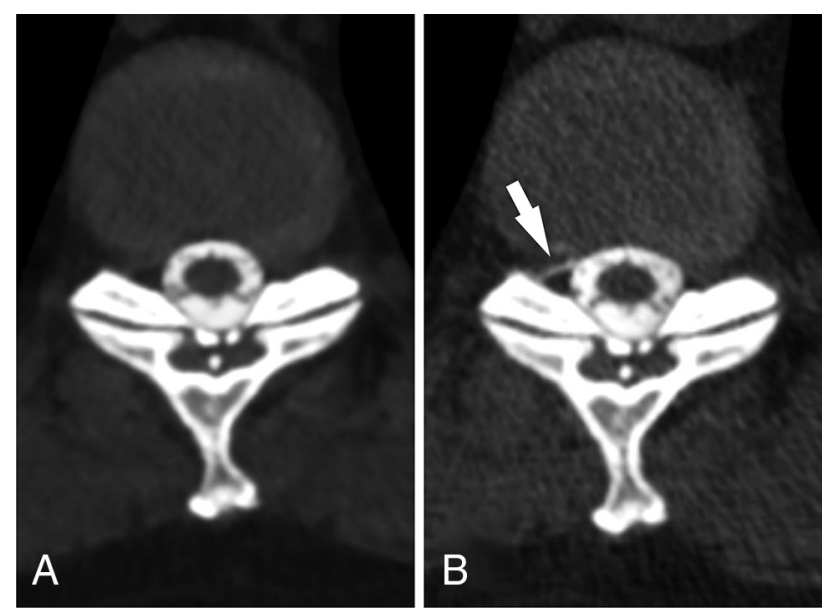

FIG 5. Low-flow CSF leak seen only on decubitus myelography. Axial prone CTM image $(A)$ shows no CSF leak at the T10-11 level. The patient was turned into the left lateral decubitus position and rescanned, again with the scan showing no leak (not shown). The patient was then turned to the right lateral decubitus position. An axial CTM image from the decubitus myelogram $(B)$ obtained 6 minutes later shows a low-flow CSF leak not seen on prone myelogram (arrow).

leaks with the patient in the decubitus position. First, when intrathecal contrast is injected and the patient is allowed to remain in the decubitus position, the contrast concentration over the leak site is higher than if the patient is rolled. This is evident from our series, in which the mean density of the intrathecal contrast at the level of the leak increased by $301 \%$ with the patient in the decubitus position compared with the prone position.
Second, there appears to be an effect of gravity that promotes the flow of contrast through a leak or into a CVF that is on the dependent side of the thecal sac. In the patient with the low-flow leak, the contrast concentration in the thecal sac only increased slightly between the prone and decubitus scans (778 versus 835 $\mathrm{HU}$ ), but the leak was only visible when the patient was in the decubitus position (Fig 5).

This investigation does not establish the sensitivity for decubitus CTM in leak detection because only cases positive for CSF leak were included in this initial report. Furthermore, it does not determine the overall additional diagnostic yield for decubitus CTM among all patients with SIH with initial negative findings on prone or supine CTM. Performing additional decubitus scans will necessarily increase the radiation dose; therefore, further investigation is needed to clarify when additional decubitus imaging is justified.

\section{CONCLUSIONS}

Decubitus CTM demonstrates CSF leaks not seen on conventional prone or supine CTM in some patients with SIH.

Disclosures: Linda Gray_UNRELATED: Board Membership: medical advisory membership for CSF Leak Association.

\section{REFERENCES}

1. Mokri B. Spontaneous low pressure, low CSF volume headaches: spontaneous CSF leaks. Headache 2013;53:1034-53 CrossRef Medline

2. Schievink WI, Moser FG, Maya MM. CSF-venous fistula in spontaneous intracranial hypotension. Neurology 2014;83:472-73 CrossRef Medline

3. Kranz PG, Luetmer PH, Diehn FE, et al. Myelographic techniques for the detection of spinal CSF leaks in spontaneous intracranial hypotension. AJR Am J Roentgenol 2016;206:8-19 CrossRef Medline

4. Cho KI, Moon HS, Jeon HJ, et al. Spontaneous intracranial hypotension: efficacy of radiologic targeting vs blind blood patch. Neurology 2011;76:1139-44 CrossRef Medline

5. Kranz PG, Tanpitukpongse TP, Choudhury KR, et al. Imaging signs in spontaneous intracranial hypotension: prevalence and relationship to CSF pressure. AJNR Am J Neuroradiol 2016;37:1374-78 CrossRef Medline

6. Schievink WI, Maya MM, Jean-Pierre S, et al. A classification system of spontaneous spinal CSF leaks. Neurology 2016;87:673-79 CrossRef Medline

7. Kranz PG, Amrhein TJ, Gray L. CSF venous fistulas in spontaneous intracranial hypotension: imaging characteristics on dynamic and CT myelography. AJR Am J Roentgenol 2017;209:1360-66 CrossRef Medline

8. Kranz PG, Amrhein TJ, Schievink WI, et al. The "hyperdense paraspinal vein" sign: a marker of CSF-venous fistula. AJNR Am J Neuroradiol 2016;37:1379-81 CrossRef Medline 